\title{
DICIONÁRIOS BILÍNGUES ESCOLARES: O TRATAMENTO DADO AOS FALSOS AMIGOS
}

\section{DICCIONARIOS BILÍNGUES ESCOLARES: EL TRATO DADO A LOS FALSOS AMIGOS}

\author{
Valeska Gracioso Carlos"
}

ResUMo: O dicionário é um instrumento fundamental para a aquisição de vocabulário e cultura de uma língua, assim, acreditamos ser quase impossível aprender uma Língua Estrangeira sem o auxílio de um ou mais dicionários. O uso de um Dicionário Bilíngue em sala de aula tem sido debatido por estudiosos da linguagem e lexicógrafos (AMARAL, 1998; DURAN, 2008; FIALHO, 2005; FERREIRA, 2006; VITAL, 2006; WERNER, 2006; XATARA, 2011; VITA, 2005). No caso do português e do espanhol, línguas com inúmeras semelhanças, esta questão ainda é mais desafiadora, sobretudo quando surgem os Falsos Amigos. Este artigo teve como objetivo analisar o tratamento dado aos Falsos Amigos em três Dicionários Bilíngues Escolares de Espanhol/Português e Português/Espanhol. Inicialmente avaliamos as propostas e em seguida verificamos qual o tratamento dados aos Falsos Amigos. Embora a Lexicografia Pedagógica e Bilíngue tenham trazido contribuições fundamentais para os Dicionários Escolares Bilíngues, as conclusões apontaram algumas falhas nas obras analisadas.

Palavras-Chave: Dicionário Bilíngue Escolar; Ensino de Língua Espanhola; Falsos Amigos.

Resumen: El diccionario es un instrumento fundamental para la adquisidor de vocabulario y cultura de una lengua, así, creemos que es casi imposible aprender una Lengua Extranjera sin el auxilio de uno o más diccionarios. El uso de un Diccionario Bilingüe en sala de clase está debatido por estudiosos del lenguaje y lexicógrafos (AMARAL, 1998; DURAN, 2008; FIALHO, 2005; FERREIRA, 2006; VITAL, 2006; WERNER, 2006; XATARA, 2011; VITA, 2005). En el caso del portugués y del español, lenguas con inúmeras semejanzas, esta cuestión se torna más desafiadora, principalmente cuando surgen los Falsos Amigos. Este artigo tuvo como objetivo analizar el tratamiento dado a los Falsos Amigos en tres Diccionarios Bilingües Escolares de Español/Portugués y Portugués/Español. Inicialmente evaluamos las

\footnotetext{
"Doutora em Estudos da Linguagem (UEL), Professora Titular Assistente da Universidade Estadual de Ponta Grossa e atua no curso de Licenciatura em Letras/Espanhol e no Mestrado em Linguagem, Identidade e Subjetividade na mesma instituição. E-mail:vgracioso@uol.com.br
} 
propuestas y a seguir verificamos cual el tratamiento dados a los Falsos Amigos. Aunque la Lexicografía Pedagógica y Bilingüe hayan traído contribuciones fundamentales para los Diccionarios Escolares Bilingües, las conclusiones apuntaran algunos fallos en las obras analizadas.

Palabras-Clave: Diccionario Bilingüe Escolar; Enseñanza de Lengua Española; Falsos Amigos.

INTRODUÇÃO

O primeiro material a ser adquirido por um aluno de Língua Estrangeira (LE) é um Dicionário Bilíngue (DB). Apontamos duas razões como iniciais: a primeira devido ao baixo custo desse material e a segunda devido à facilidade de se encontrar esse tipo de obra. No entanto, surgem grandes preocupações por parte do professor diante dessa atitude: será que o aluno fez a melhor escolha do dicionário? Não seria melhor investir em um dicionário monolíngue de LE? Cabe ao professor a responsabilidade de indicar a obra?

Essas questões têm sido amplamente discutidas por estudiosos da linguagem e lexicógrafos (AMARAL, 1998; DURAN, 2004, 2008; HÖFLING, SILVA, TOSQUI, 2004; FIALHO, 2005; FERREIRA, 2006; VITAL, 2006; WERNER, 2006; XATARA, 2001, 2011; VITA, 2005). Muitos professores resistem ao uso do dicionário bilíngue devido aos vários problemas apresentados em suas equivalências. Contudo, estudos comprovam que os dicionários bilíngues são mais utilizados nos níveis iniciais da aprendizagem de Língua Estrangeira, por dois motivos, ou os alunos iniciantes não se sentem competentes para a leitura na Língua Estrangeira ou não entendem as definições apresentadas pelo dicionário monolíngue. (Schmitz, 1998).
Desta forma, é imprescindível que o professor esteja preparado para orientar seus alunos na escolha de um bom dicionário e que tenha conhecimentos de como utilizá-lo em sala de aula. Nossa preocupação parte do pressuposto de que os alunos apresentam dificuldades ou ainda não sabem como utilizar os dicionários bilíngues. Ainda, acreditamos que o professor não possui formação adequada para essa tarefa, o que dificulta ainda mais o uso do dicionário (Silva, 2011).

Nossa experiência corrobora com o que referimos acima, pois como professora de Língua Espanhola de um curso de Letras Português/Espanhol, presenciamos diariamente a dificuldade que nossos alunos apresentam ao escolher o vocábulo adequado para sua produção escrita, sobretudo no primeiro ano.

Sendo a Língua Portuguesa e a Língua Espanhola línguas irmãs, provenientes do Latim, consideradas como as mais semelhantes das Línguas Românicas, estas possuem um vasto léxico em comum. Contudo, surgem dessas semelhanças e/ou das poucas diferenças o que chamamos de Falsos Amigos, que são verdadeiras armadilhas para os estudantes brasileiros de Língua Espanhola.

Assim, temos como objetivo para esta pesquisa analisar comparativamente o tratamento dado aos Falsos Amigos em três 
dicionários escolares bilíngues espanhol/ português, português/espanhol como material paradidático de apoio para a aprendizagem da Língua Espanhola por falantes do português.

\section{Dicionários Bilíngues Pedagógicos}

O dicionário de língua faz uma descrição do vocabulário da língua em questão, buscando registrar e definir os signos lexicais que referem os conceitos elaborados e cristalizados na cultura. Por outro lado, o dicionário é um objeto cultural de suma importância nas sociedades contemporâneas, sendo uma das mais relevantes instituições da civilização moderna. Exercendo funções normativas e informativas na sociedade, esse produto cultural deveria ser de uso obrigatório para todos os usuários da língua. (BIDERMAN, 1998, p. 15-16)

O dicionário de língua é um instrumento fundamental para a aquisição de vocabulário e cultura de uma língua, deste modo, acreditamos ser quase impossível aprender uma Língua Estrangeira sem o auxilio de um ou mais dicionários. Nossa experiência demonstra que nos níveis iniciais os Dicionários Bilíngues são de grande ajuda, desde que sua escolha seja adequada para o propósito do ensino aprendizagem da LE. Nos níveis intermediários, uma vez que o aluno já tenha o domínio básico da estrutura da LE, os dicionários semibilíngues passam a ser uma alternativa bastante efetiva. Já para o aluno que se encontra em um nível avançado, os dicionários monolíngues de LE devem ser utilizados, o que não significa descartar o uso dos dicionários anteriores. Ademais, ressaltamos que além da utilização dos dicionários de LE, muitas vezes o aluno precisa recorrer ao dicionário de Língua Materna para assegurar sua compreensão.

Em poucas palavras poderíamos definir um dicionário bilíngue sendo um tipo de dicionário que traz as equivalências ou a tradução da palavra na língua alvo. No entanto, com o avanço das ciências do léxico esse cenário está sendo modificado. A lexicografia pedagógica e bilíngue têm contribuído muito para esse avanço à medida que direcionam a obra lexicográfica a um determinado propósito e público alvo: o ensino e o aluno. Conforme Duran (2004), a Lexicografia Bilíngue

(...) tem apresentado diversas inovações que auxiliam o estabelecimento de associações e a descoberta de aspectos pragmáticos relacionados com o léxico, pois oferecem contextualizações e mais uma série de informações especialmente elaboradas, tendo em mente as dificuldades do aprendiz de língua estrangeira. (DURAN, 2004, p. 49)

Para tratar do dicionário bilíngue no ensino aprendizagem de Língua Espanhola teremos antes refletir sobre as relações de proximidade entre as línguas em questão.

PoRTUGUês E ESPANHOL: LÍNGUAS PRÓXIMAS

Como mencionado anteriormente, a Língua Espanhola e a Língua Portuguesa pertencem à mesma família. Provenientes do Latim se desenvolveram na Península Ibérica e tiveram uma evolução paralela. Segundo 
Almeida Filho (2001), "a ordem canônica da oração nas duas línguas é altamente coincidente, a fonte maior do léxico é basicamente a mesma e as bases culturais onde se assentam são em larga medida compartilhadas" (ALMEIDA FILHO, 2001, p. 14-15). No entanto, a proximidade entre as duas línguas não é uniforme, a maior semelhança está no léxico. O autor ainda afirma, por meio de Ulsh, que tais línguas apresentam mais de $85 \%$ do vocabulário em comum. (Ulsh apud Almeida Filho, 2001, p. 15)

Deste modo, um falante nativo da Língua Portuguesa, não apresentaria muitas dificuldades para aprender a Língua Espanhola. Na verdade, os aprendizes brasileiros de Língua Espanhola apresentam uma facilidade inicial para a aprendizagem dessa língua em relação a falantes de outros idiomas. Contudo, essa facilidade faz com que muitas vezes o aprendiz fique aprisionado em uma interlíngua ${ }^{1}$, sem conseguir uma proficiência. Conforme Carmolinga (2005),

(...) a vantagem inicial, quando da aprendizagem de uma língua cognata, nem sempre (aliás, raras vezes) culmina no domínio quase perfeito e rápido da língua visada. Muito pelo contrário, o mais provável é estacionar numa interlíngua, mais ou menos distante da meta. (CARMOLINGA, 2005, p. 199)

Sobre a questão discorre Neta (2010) em seu texto "Aprender español es fácil porque hablo portugués: Ventajas y desventajas de

\footnotetext{
${ }^{1}$ Para esse trabalho entendemos interlíngua como uma língua intermediária entre o português e o espanhol, resultante do aprendizado de uma das duas línguas, chamado de maneira generalizada de portunhol.
}

los brasileños para aprender español”. Ainda autora afirma que:

si por un lado las semejanzas hacen que los lusohablantes avancen más rápidamente (normalmente los brasileños no son principiantes absolutos), por otro, son también muy constantes los errores interlinguales y su posible fosilización. Surge el portuñol que tomado desde una perspectiva positiva es una señal de progreso (interlengua); en otros casos, sin embargo, el hablante asume ese nivel de interlengua como suficiente para comunicarse y ya no busca progresar. (NETA, 2010, s/p.)

Assim sendo, podemos considerar o aprendiz brasileiro de Língua Espanhola como um falso iniciante, pois mesmo sem o conhecimento da Língua Espanhola, desde o primeiro contato com a língua, seja no primeiro dia de aula, ou em uma conversa com um nativo, já consegue compreender e se expressar na LE. Muitas interferências poderão surgir nesse período inicial de aprendizagem, não obstante, nesse começo colabora para aprendizagem que atrapalha. (Carmolinga, 1997; Contreras, 2001)

Portanto, para que a aprendizagem da Língua Espanhola seja mais efetiva é de fundamental importância que haja materiais pedagógicos específicos para o ensino-aprendizagem da língua para brasileiros.

Se é no léxico que existem as maiores semelhanças entre as línguas, então o Dicionário Bilíngue deveria enfatizar os vocábulos que são diferentes e não somente nas palavras que apresentam as mesmas equivalências em ambas as línguas. 


\section{Falsos Amigos}

São chamadas de Falsos Amigos as palavras que possuem a mesma aparência nas duas línguas, mas que, entretanto, apresentam significados diferentes. Muitos autores têm tratado a questão dos Falsos Amigos na aprendizagem dessas línguas irmãs (CONTRERAS, 1998; CEOLIN, 2003; VITA, 2004; CARMOLINGA, 2005; KREBS, 2007; BUGUEÑO, 2008), entretanto muitas opiniões se divergem com respeito aos diferentes nomes dado ao fenômeno.

Para esse trabalho entendemos Falsos Amigos, Falsos Cognatos e Heterossemânticos como sinônimos. Tomamos a definição de Hoyos Andrade dada no prólogo de Dicionário de Falsos Amigos do espanhol e do português de Balbina Lorenzo Feijó Hoyos:

Se entiende por Falsos Amigos aquellas palabras que por semejanza ortográfica y/o fónica parecen a primera vista fáciles de ser entendidas, traducidas o interpretadas, pero que de hecho esconden peligrosas trampas de sentido para el incauto lector o traductor. (FEIJÓ HOYOS, 1992, p. 8)

Segundo o autor, não existe apenas uma classe de Falsos Amigos. Os tipos mais comuns são aquelas palavras que apesar de sua forma semelhante ou idêntica não apresenta nenhum significado comum nas duas línguas confrontadas. É o que acontece, por exemplo, com as palavras taller ${ }^{2} /$ talher, no caso do espanhol e português. Contudo,

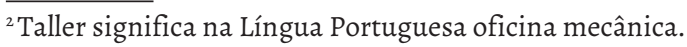

conforme o autor, esse tipo de Falso Amigo não é o mais comum, pelo menos ao se tratar do português e do espanhol. Os tipos mais frequentes são aquelas palavras que têm algum ou alguns significados iguais e outros diferentes. Às vezes o problema pode ser uma questão de uso. É o que acontece com o adjetivo torpe, em espanhol é mais utilizado com o sentido de "falta de habilidade, que se move com dificuldade"; já em português com o sentido de "impudico, desonesto, infame, vergonhoso"; porém, não significa que essa palavra, em alguns casos, não tenha os mesmos valores que são predominantes na outra língua.

Podemos exemplificar o que foi dito acima com as palavras do espanhol "cerrar" e "firmar", que em português significam respectivamente "fechar" e "assinar". Em espanhol "cerramos las puertas y las ventanas" e "firmamos un contrato"; em português "fechamos portas e janelas" e "assinamos um contrato". Entretanto, dizemos "as inscrições estão encerradas" e "reconhecemos firma".

Isso ocorre devido à evolução das línguas dentro da Península Ibérica cujo processo diacrônico direcionou as seleções lexicais do português e do espanhol de forma diferenciada. Devemos recordar que as línguas estão em constantes mudanças e que estas ocorrem de forma lenta e gradual. Assim sendo, as escolhas históricas da Língua Portuguesa nem sempre coincidiram com as da Língua Espanhola. No entanto, resquícios do de um tronco comum ainda podem ser presenciados como é o caso dos exemplos acima.

Deste modo, acreditamos ser de suma importância que uma obra lexicográfica 
pedagógica bilíngue deva enfatizar diferenças e salientar os Falsos Amigos das línguas contrastadas para facilitar as escolhas lexicais que o aprendiz fará na sua produção seja oral ou escrita.

\section{Metodologia}

Para este trabalho analisamos três Dicionários Bilíngues Escolares focalizando o tratamento dado aos Falsos Amigos.

Em um primeiro momento, fazemos uma breve avaliação da apresentação dos dicionários, verificando, assim, as informações que trazem ao usuário. Em um segundo momento, analisamos as entradas com o objetivo de verificar o tratamento dado por esses dicionários aos Falsos Amigos.

A escolha dos verbetes, necessariamente Falsos Amigos, foi pautada nas dificuldades e erros frequentes cometidos por nossos alunos durante o processo inicial de aquisição da língua irmã. Por conseguinte, analisamos comparativamente nos três dicionários 6 (seis) Falsos Amigos nas entradas da Língua Espanhola: Apellido, Asignatura, Escritorio, Oficina, Salsa e Vaso, e 6 (seis) Falsos Amigos nas entradas da Língua Portuguesa: Apelido, Escritório, Assinatura, Oficina, Salsa e Vaso.

Desta forma, tratamos somente a classe dos substantivos, chamados Falsos Amigos Lexicais, não adentrando no campo dos Falsos Amigos Estruturais ${ }^{3}$.

Os Dicionários Bilíngues Escolares analisados foram o Minidicionário espanhol português, português / espanhol da editora

\footnotetext{
${ }^{3}$ Sobre o tema ver: Falsos Amigos Estruturais entre o Português e o Castelhano de Roberto Ceolin
}

Ática, o Dicionário Santilhana para estudantes: espanhol português, português / espanhol, e o Minidicionário Larousse espanhol português, português / espanhol.

A escolha dos dicionários de deu pelo fato de serem os mais utilizados por nossos alunos no momento em que iniciam a graduação de Letras Português/ Espanhol.

\section{DisCUSSÃO DOS DADOS}

Análise da Apresentação dos

Dicionários Bilíngues Escolares

Nesta etapa, para uma melhor compreensão por parte do leitor, analisamos os dicionários separadamente com o intuito de verificar o que trazem em sua apresentação. Averiguamos se mencionam o público alvo, a quantidade de verbetes, o tratamento dado aos Falsos amigos, se há bibliografia consultada e outras informações relevantes ao usuário para a compreensão da obra.

ÁTICA

O Minidicionário da editora Ática em sua apresentação elucida que está orientado a estudantes brasileiros de nível médio, no entanto não há esclarecimentos do que venha a ser nível médio. Podemos supor que seja direcionado aos alunos que estão no Ensino Médio ou aos alunos que estão em um nível intermediário de aprendizagem da Língua Espanhola. Contudo, informa que foi elaborado especialmente para o estudante brasileiro.

Conforme sua apresentação, contém cerca de 20 mil verbetes, sendo $10 \mathrm{mil} \mathrm{em}$ cada língua. $\mathrm{O}$ critério para a escolha dos 
verbetes utilizados foi o da frequência de uso, não obstante não há informações sobre a forma de seleção utilizada ou sobre a origem dos dados.

Ainda, esclarece que inclui espanholismos, americanismos, regionalismos, termos técnicos, jurídicos, científicos e coloquiais, expressões idiomáticas e provérbios, com respectiva tradução ou adaptação ao idioma oposto, e apêndices de uso prático.

A sequência dos verbetes segue a ordem alfabética, incluindo como letras o $l l$ e o ch, considerados atualmente pela Real Academia Espanhola (RAE) como dígrafos. Contudo, a letra ñ encontra-se separada da letra $n$.

A entrada, em negrito, inclui divisão silábica (de-sa-rro-llo) e indicação da silaba tônica para os vocábulos heterotônicos, ou seja, aqueles que têm sílabas tônicas diferentes das do português (de-mo-cra-cia). Além disso, aparecem indicação de feminino (a-lum-no/na) e de feminino irregular (ac-tor / ac-triz), e símbolo para indicação de Falso Amigo ${ }^{4}$.

fa.ro s.m 1. Farol, torre que guia os navios. 2. Farol, lanterna de automóvel. 3. Fig. Guia, rumo.

A entrada é seguida de sua categoria gramatical (taxionomia) em abreviaturas (ár-bol s.m.), caso o verbete assuma categorias diversas, mas conserva o mesmo significado, a classificação aparece após a entrada do verbete (bien-ve-ni-do/a adj. 1. Bem-vindo. $\bullet$ s.f.

${ }^{4}$ As autoras consideram Falso Amigo como sinônimo de Falso Cognato.
2. Boas-vindas). Quando houver o campo de indicação do termo este é indicado logo após a taxionomia (cho-lo s.m. 1. Tamanco de madeira. 2. Bot. Amer. Milho verde). Os exemplos em itálico visam a destacar um significado, uso da regência que difere do português (her-vi-do/a adj. 1. fervido. • s.m. 2. Prato cozido. Haré um hervido de cena. Farei alguma coisa cozida no jantar.)

As entradas do português/espanhol são mais simples e diretas. De acordo com as autoras o objetivo fundamental da obra foi a de dar versões para o espanhol. Desta forma, as entradas, em negrito, seguindo a ordem alfabética do português, não incluem divisão silábica, nem o gênero feminino.

O dicionário em questão também apresenta: sinais gráficos, alfabeto (português/ espanhol), regras da divisão silábica, quadro fonológico, acentuação gráfica (português/ espanhol), e abreviaturas. Ao final podemos encontrar uma breve explicação sobre os falsos cognatos seguidos de uma lista de falsos amigo que foram considerados relevantes pelas autoras. Ademais, traz modelos de conjugação verbal, numerais cardinais e ordinais, adjetivos pátrios, pronomes e formas de tratamento (Brasil, América e Espanha) e referências bibliográficas.

Podemos considerar o Minidicionário da Ática um bom dicionário para o aluno iniciante aprendiz da Língua Espanhola, pois possui uma microestrutura bem desenvolvida, o que facilita a compreensão de como ser utilizado pelo aluno. Além disso, traz exemplos práticos e claros, auxiliando na compreensão e produção na Língua Estrangeira. A obra não traz transcrições fonéticas, o que 
julgamos não ser necessário na etapa inicial do aprendizado.

\section{SANTILHANA}

O Dicionário Santilhana para Estudantes elucida em sua apresentação a dificuldade encontrada pelos lexicógrafos em elaborar uma obra bilíngue de línguas tão semelhantes. Os autores afirmam que a obra deve facilitar aos estudantes brasileiros a compreensão da Língua Espanhola e, portanto, dão maior destaque à língua que se está aprendendo: o espanhol. Ainda salientam que a simples transcrição de palavras de uma língua à outra, sobretudo tratando-se do português e do espanhol, pouco se esclarece a quem consulta um dicionário. Deste modo, optaram por oferecer, de maneira sucinta, o(s) significado(s) ou acepção(ções) de cada vocábulo.

No caso de vocábulos que apresentam inúmeras definições os autores optaram em selecionar a(s) acepção(ções) que com maior frequência se emprega $(\mathrm{m})$ em detrimento das de menor frequência.

Após a apresentação o dicionário apresenta um guia de como está estruturado, com o intuito de auxiliar o consulente quanto sua utilização.

A sequência dos verbetes segue a ordem alfabética, do alfabeto espanhol, em sua estrutura atual, incluindo o 11 dentro da letra $\mathbf{L}$ e o ch dentro da letra $\mathbf{C}$.

A entrada, em negrito, inclui divisão silábica e indicação da silaba tônica para todos os vocábulos (de-sa-rro-llo).

Nas entradas há sinônimos, locuções, refrães e expressões idiomáticas mais usuais.
Podemos encontrar também na obra analisada a classe gramatical da palavra, o gênero e o número do substantivo. No caso dos verbos há uma remissão ao modelo de conjugação verbal. Quando há mais de uma acepção esta é diferenciada em negrito. Os exemplos são dados em itálico. Os falsos cognatos estão indicados pelo símbolo, em vermelho, assim como as entradas.

$\square$ ga.nan.cio.so, sa adj. Que apresenta ganhos. Lucrativo

Nesta obra são apresentados modelos de conjugação verbal, apêndices organizados segundo critérios semânticos e discursivos, como o campo léxico das profissões ou do corpo humano. O dicionário contempla ainda uma lista de países e nacionalidades, números cardinais e ordinais, símbolos matemáticos, abreviaturas e o gênero comunicativo das cartas escritas.

Um ponto positivo que traz o Dicionário Santilhana é a remissão à conjugação verbal, que é uma das maiores dificuldades encontradas por nossos alunos não só em um estágio inicial como também durante todo o aprendizado. Portanto, acreditamos que este seja um dicionário adequado a alunos iniciantes aprendizes de espanhol. No entanto, uma falha que constatamos é que sua apresentação não elucida sobre a quantidade dos verbetes e tampouco há referência de onde foram retirados os corpora das Línguas Espanhola e Portuguesa. 


\section{LAROUSSE}

Em sua apresentação o Mini Dicionário Larousse informa que é a referência ideal para estudantes brasileiros nos primeiros anos do aprendizado da Língua Espanhola. Possui 30.000 palavras e expressões e mais de 40.000 traduções. Ainda segundo sua apresentação o dicionário informa que é um bom instrumento para auxiliar o estudante a compreender diversos tipos de texto uma vez que as palavras são sempre apresentadas em seu contexto.

Apresenta logo nas primeiras páginas um guia "Como usar este dicionário", no qual esclarece ao consulente detalhes sobre sua utilização.

As entradas encontram-se em negrito e seguem a ordem alfabética do alfabeto internacional incluindo como letras o ll e o ch. No entanto, considera o $\tilde{\mathbf{n}}$ uma letra independente do $\mathbf{n}$. A entrada é seguida de sua categoria gramatical (taxionomia) em abreviaturas (árbol $m$ ). Não há divisão silábica, indicação de sílaba tônica ou transcrição fonética das palavras nas entradas.

Os Falsos Amigos apresentam um tratamento especial. Logo após a definição, quando há, vem o equivalente na outra língua, seguido de um box explicativo, que contrasta as duas línguas e traz exemplos contextualizados.

\section{escoba $f$ vassoura}

[Não confundir escoba (vassoura) com o português escova que em espanhol é cepillo. Necesito una escoba para varrer el suelo. Preciso de uma vassoura para varrer o chão.]
O dicionário ainda oferece um suplemento com breves explicações gramaticais sobre os substantivos, acentuação, artigos, adjetivos, pronomes, preposições, advérbios e modelos de conjugação verbal e uma lista de Falsos Amigos, além de trazer conhecimentos sobre a América Latina/ América Hispânica. Ainda oferece uma seção chamada "o idioma em ação" que auxilia o estudante na comunicação falada e escrita que contém exemplos de conversação telefônica, modelos de carta, numerais cardinais e ordinais, data e hora e apresentações pessoais.

A obra está bem estruturada e apresenta explicações claras e objetivas. Uma vantagem desse dicionário com relação aos Falsos Amigos é o contraste que se faz entre as duas línguas com os exemplos contextualizados, ilustrado anteriormente, o que facilita a compreensão do uso do vocábulo pelo estudante. Não obstante, este dicionário não esclarece sobre a bibliografia consultada e tampouco qual a fonte dos dados.

\section{Análise das Entradas com Falsos Amigos}

Como dito anteriormente, a escolha dos vocábulos foi pautada nas dificuldades e erros frequentes cometidos por nossos alunos durante o processo inicial de aquisição da língua irmã. Elegemos 6 (seis) vocábulos para cada língua dentre muitos dos Falsos Amigos que são considerados vilões do aprendizado da Língua Espanhola por falantes do português. Nesta seção, optamos por comparar cada vocábulo nos três dicionários para uma melhor visualização. 
Apresentamos a tabela com as entradas na Língua Espanhola, após teceremos nossos comentários. Tratamos cada entrada nos três dicionários com o objetivo de compará-las.

\begin{tabular}{|c|c|c|}
\hline Ática ${ }^{5}$ & Santilhana & Larousse \\
\hline $\begin{array}{l}\text { A.pe.lli.do s.m. Sobrenome, nome } \\
\text { de família. Su apellido es Santos. Seu } \\
\text { sobrenome é Santos. Con nombre } \\
\text { y apellido. Com todos os dados/ } \\
\text { detalhes. }\end{array}$ & $\begin{array}{l}\text { A.pe.lli.do } m \text {. nome de família } \\
\text { com que se identificam as } \\
\text { pessoas. } \\
\text { Sobrenome. Sus apellidos son } \\
\text { Pérez y Rojas; Pérez por parte de } \\
\text { padre y Rojas por parte de madre. } \\
\text { Seus sobrenomes são Pérez e } \\
\text { Rojas; Pérez por parte de pai e } \\
\text { Rojas por parte de mãe. }\end{array}$ & $\begin{array}{l}\text { apellido } m \text { sobrenome } m \text {. [Não } \\
\text { confundir apellido (sobrenome) com } \\
\text { o português apelido que em espanhol } \\
\text { é apodo. (El apellido de mis primos } \\
\text { es González. O sobrenome dos meus } \\
\text { primos é González)] }\end{array}$ \\
\hline $\begin{array}{l}\text { A.sig.na.tu.ra s.f. Disciplina, } \\
\text { matéria de estudos, cadeira. }\end{array}$ & $\begin{array}{l}\text { A.sig.na.tu.ra f. cada uma } \\
\text { das áreas que compõem o } \\
\text { programa de um curso em um } \\
\text { estabelecimento de ensino. } \\
\text { Disciplina. }\end{array}$ & $\begin{array}{l}\text { asignatura } f \text { matéria } f \text { de estudo, } \\
\text { disciplina } f \text {. }\end{array}$ \\
\hline $\begin{array}{l}\text { O.fi.ci.na s.f. 1. Escritório. Trabaja } \\
\text { en una oficina. Trabalha em um } \\
\text { escritorio. 2. Repartição. Quiero que } \\
\text { se presente en una oficina de Hacienda. } \\
\text { Quero que ele se apresente numa } \\
\text { repartição da Fazenda. 3. Agência. } \\
\text { La oficina de correos es cerca de aquí. A } \\
\text { agência do correio é perto daqui. 4. } \\
\text { Sala, conjunto. La empresa está situada } \\
\text { en la calle Europa, número 5, oficina } \\
\text { 2. A empresa está localizada na rua } \\
\text { Europa, número 5, sala } 2 \text {. }\end{array}$ & $\begin{array}{l}\text { O.fi.ci.na } f \text {. } 1 \text {. Local de trabalho } \\
\text { em atividades administrativas. } \\
\text { Escritório. 2. Departamento } \\
\text { ou repartição pública. } \\
\text { Escritório. }\end{array}$ & $\begin{array}{l}\text { oficina } f \text { (de profissional) escritório } \\
m \text { (em empresa, instituição) agência } \\
f \text { oficina de correos agência de } \\
\text { correios; oficina de objetos perdidos } \\
\text { setor } m \text { de achados eperdidos; oficina } \\
\text { de turismo agência de turismo. } \\
\text { [Não confundir com o português } \\
\text { 'oficina', que tem um significado } \\
\text { similar ao espanhol taller: (Mi } \\
\text { secretaria se encuentra en la oficina } \\
\text { de } 9 \text { a } 17 \text { horas. Minha secretária } \\
\text { encontra-se no escritório das } 9 \text { às } 17 \\
\text { horas.)] }\end{array}$ \\
\hline $\begin{array}{l}\text { Es.cri.to.rio s.m. 1. Escrivaninha. 2. } \\
\text { Porta-jóias. 3. Despacho, escritório, } \\
\text { sala. }\end{array}$ & $\begin{array}{l}\text { Es.cri.to.rio } m \text {. Móvel para } \\
\text { escrever, que se usa para o } \\
\text { trabalho. } \\
\text { Escrivaninha. } \rightarrow \text { Muebles }^{6}\end{array}$ & $\begin{array}{l}\text { escritorio } m \text { escrivaninha } f \text { [Note } \\
\text { que escritório também significa em } \\
\text { espanhol móvel para escrever, fazer } \\
\text { tarefas de escritório, etc.: (Tenía mucho } \\
\text { trabajo esperando sobre el escritorio. } \\
\text { Tinha muito trabalho esperando } \\
\text { sobre a escrivaninha.)] }\end{array}$ \\
\hline
\end{tabular}

${ }^{5}$ Todas as palavras do Dicionário Ática apresentam o sinal da mãozinha indicando que se trata de um Falso Amigo, com exceção do vocábulo VASO.

${ }^{6} \mathrm{O}$ símbolo $\rightarrow$ indica que a palavra aparece nos apêndices visuais do dicionário. 


\begin{tabular}{|c|c|c|}
\hline Ática ${ }^{5}$ & Santilhana & Larousse \\
\hline $\begin{array}{l}\text { Sal.sa s.f. 1. Molho. Salsa de tomate. } \\
\text { 2. Fig. Graça, leveza. 3. Mus. Ritmo e } \\
\text { dança do norte da América do Sul. } \\
\text { Salsa Bechamel/Besamel. Molho } \\
\text { bechamel. Salsa blanca/ vinagreta. } \\
\text { Molho branco/vinagrete. }\end{array}$ & $\begin{array}{l}\text { Sal.sa f. 1. Cul. Composição de } \\
\text { várias substâncias que se faz } \\
\text { para condimentar e acompanhar } \\
\text { outros alimentos. Molho. } \\
\text { 2. Tipo de música e dança } \\
\text { caribenha. Salsa. Salsa } \\
\text { blanca. Cul. Molho branco. Salsa } \\
\text { tártara. Cul. Molho tártaro. }\end{array}$ & $\begin{array}{l}\text { salsa } f \text { (para comidas) molho } m \text { (graça) } \\
\text { tempero } f \text { (baile, música) salsaf; salsa } \\
\text { bechamel molho branco; salsa rosa } \\
\text { molho rosa; salsa de tomate molho } \\
\text { de tomate; salsa verde molho verde; } \\
\text { salsa vinagreta molho vinagrete. } \\
\text { [Não confundir salsa (molho) com o } \\
\text { português salsa que em espanhol é } \\
\text { perejil. (La abuela cocina salsas con } \\
\text { muchos ingredientes. A vovó cozinha } \\
\text { os molhos com muitos ingredientes)] }\end{array}$ \\
\hline $\begin{array}{l}\text { Va.so s.f. 1. Copo. Un vaso de agua. } 2 . \\
\text { Med. Vaso, conducto. 3. Vaso, jarra. } \\
\text { Ahogarse en un vaso de agua. Fazer } \\
\text { tempestade em copo d'água. }\end{array}$ & $\begin{array}{l}\text { Va.so } f \text {. } 1 .{ }^{\square} \text { Recipiente de metal, } \\
\text { vidro ou outro material que serve } \\
\text { para levar à boca líquidos que } \\
\text { serão bebidos. } \\
\text { Copo. 2. Conducto por onde } \\
\text { circula, nos vegetais, a seiva ou o } \\
\text { látex. Vaso. 3. Anat. Conducto } \\
\text { pelo qual circula o sangue e a } \\
\text { linfa no corpo dos animais. } \\
\text { Vaso. } \\
\text { Ahogarse en un vaso de agua. } \\
\text { Fazer tempestade em um copo } \\
\text { d'água. }\end{array}$ & $\begin{array}{l}\text { vaso } m \text { copo } m \\
\text { [Não confundir vaso (copo) com o } \\
\text { português vaso que em espanhol é } \\
\text { florero. (Compré una docena de vasos } \\
\text { nuevos para tomar agua. Comprei } \\
\text { uma dúzia de copos novos para tomar } \\
\text { água.)] }\end{array}$ \\
\hline
\end{tabular}

A primeira entrada, o Falso Amigo Apellido, está bem definido e explicado, os dicionários trazem seu equivalente na Língua Portuguesa e, ainda, exemplos contextualizando o vocábulo. Todos os dicionários indicam que a palavra é um Falso Amigo. O dicionário Larousse faz um contraste entre apellido (sobrenome) ${ }^{7}$ e apodo (apelido).

Já na palavra Asignatura não há exemplos, apenas equivalentes. O único dicionário que apresenta sua definição é o Santilhana. $O$ dicionário Larousse não indica que a palavra é um Falso Amigo.

A entrada para a palavra Oficina é mais complexa, pois a palavra apresenta mais de uma acepção. O dicionário da Ática traz quatro acepções enquanto os outros dois trazem apenas duas, as mais frequentes. O vocábulo está considerado como Falso Amigo, entretanto está contextualizado com exemplos apenas pelo Ática e Larousse. Este último ainda faz o contraste entre oficina (escritório) e taller (oficina mecânica).

A palavra Escritorio contém apenas seus equivalentes no dicionário da Ática. Já no Santilhana há uma definição seguida de seu equivalente, no entanto esse dicionário não considera nenhuma acepção como Falso Amigo. A entrada encontra-se mais completa no dicionário Larousse que apresenta seu equivalente na Língua Portuguesa seguido do box explicativo que contém definição e exemplos.

\footnotetext{
${ }^{7}$ As palavras entre parênteses estão em português.
} 
O quinto verbete, Salsa, está considerado como Falso Amigo por todos os dicionários analisados. O dicionário Ática apresenta três acepções, estando a segunda (2. Fig. Graça, leveza.), por falta de exemplos e contextualização, não muito clara. Os outros dicionários trazem apenas duas acepções, talvez as mais usuais. As demais definições estão claras e ainda o dicionário Larousse atenta em seu box para as diferenças entre salsa (molho) e perejil (salsa/salsinha).

A sexta e última entrada analisada, a palavra Vaso, não é considerada Falso Amigo pelo dicionário da Ática em nenhuma de suas acepções, apresenta apenas seus equivalentes. O dicionário Santilhana já traz definições e, assim como o Ática, apresenta três acepções. Ambos trazem uma expressão idiomática com o vocábulo. Já o dicionário Larousse proporciona apenas seu equivalente, no entanto apresenta exemplos e faz o contraste entre as duas línguas: vaso (copo) e florero (vaso).

Como podemos notar os dicionários seguem a padronização proposta em suas apresentações, no entanto, encontramos algumas falhas. Ainda que não em todas as acepções, a palavra Vaso deve ser considerada um Falso Amigo quando seu equivalente é copo, o que não ocorre no dicionário Ática. Na palavra Escritorio falta o sinal indicativo de Falso Amigo no dicionário Santilhana, ainda que haja o sinal gráfico que remeta o verbete ao glossário visual. As entradas carecem de exemplos como é o caso da segunda acepção da palavra Salsa (2. Fig. Graça, leveza.), será que o consulente saberia utilizar essa acepção tão pouco usual?

Passamos para a tabela com as entradas na Língua Portuguesa, após teceremos nossos comentários com relação aos verbetes.

\begin{tabular}{|c|c|c|c|}
\hline Ática & Santilhana & & Larousse \\
\hline Apelido s.m. Apodo & $\begin{array}{l}\text { Apelido } m . \\
\text { sobrenombre. }\end{array}$ & Apodo, & $\begin{array}{l}\text { apelido } m \text { (alcunha) apodo } m \\
\text { [Não confundir apelido (apodo) } \\
\text { com o espanhol apellido que em } \\
\text { português é sobrenome. (O apelido } \\
\text { de Edson Arantes do Nascimento é } \\
\text { Pelé. El apodo de Edson Arantes } \\
\text { do Nascimento es Pelé.)] }\end{array}$ \\
\hline $\begin{array}{l}\text { Escritório s.m. oficina, despacho, } \\
\text { agencia. } \quad \text { Escritório de } \\
\text { advogado. Bufete, estudio, } \\
\text { escritorio, firma forense. }\end{array}$ & $\begin{array}{l}\text { Escritório } \quad m . \\
\text { despacho; agencia. }\end{array}$ & Oficina; & $\begin{array}{l}\text { escritório } m \text { (de casa, advogado) } \\
\text { despacho } m \text {. Esp, estudio m Amér; } \\
\text { (de empresa) oficina f; (mesa) } \\
\text { escritorio } m \text {. } \\
\text { [Note que escritorio em espanhol } \\
\text { também significa 'móvel para } \\
\text { escrever, fazer tarefas de escritório': } \\
\text { (Tenía mucho trabajo esperando } \\
\text { sobre su escritorio. Tinha muito } \\
\text { trabalho esperando sobre sua } \\
\text { escrivaninha.)] }\end{array}$ \\
\hline
\end{tabular}




\begin{tabular}{|c|c|c|}
\hline Ática & Santilhana & Larousse \\
\hline $\begin{array}{l}\text { Assinatura } s . f . \text { 1. Firma. Assinatura } \\
\text { reconhecida. Firma legitimada. } 2 . \\
\text { Subscripción, abono. }\end{array}$ & $\begin{array}{l}\text { Assinatura f. 1. Firma. 2. } \\
\text { Subscripción; abono. }\end{array}$ & $\begin{array}{l}\text { assinatura } f \text { (nome escrito) firma } f ; \\
\text { (de revista) suscripción } f \text {. }\end{array}$ \\
\hline $\begin{array}{l}\text { Oficina s.f. Taller. Oficina } \\
\text { mecânica. Taller mecánico. }\end{array}$ & $\begin{array}{l}\text { Oficina } f . \text { Taller. Oficina } \\
\text { mecánica. Taller mecánico. }\end{array}$ & $\begin{array}{l}\text { oficina } m 3 \text { taller } m \text { mecánico Esp } \\
\text { \&RP, refaccionaria } f \text { Méx. } \\
\text { [Não confundir com o espanhol } \\
\text { oficina, que refere-se a um } \\
\text { lugar onde se faz trabalho } \\
\text { administrativo (Dejé el auto en } \\
\text { el taller mecánico para que lo } \\
\text { arreglaran. Deixei o carro na } \\
\text { oficina mecânica para que o } \\
\text { consertassem.; Mi secretaria } \\
\text { se encuentra en la oficina de } 9 \\
\text { a } 17 \text { horas. Minha secretária } \\
\text { encontra-se no escritório das } 9 \text { às } \\
17 \text { horas.)] }\end{array}$ \\
\hline Salsa s.f. Bot. Perejil. & Salsa f. Bot. Perejil. & $\begin{array}{l}\text { salsa } f \text { perejil } m \\
\text { [Não confundir Salsa (perejil) } \\
\text { com o espanhol salsa que em } \\
\text { português é molho. (Maria usou } \\
\text { salsa para temperar o frango. } \\
\text { María usó perejil perejilt4 para } \\
\text { condimentar el pollo.)] }\end{array}$ \\
\hline $\begin{array}{l}\text { Vaso s.m. 1. Florero, jarrón (de } \\
\text { vidro, cristal). 2. Maceta, tiesto } \\
\text { (de barro, xaxim). 3. Med. Vaso, } \\
\text { arteria, ducto. 4. Mar. Buque. } \\
\text { Vaso sanitário. Inodoro. }\end{array}$ & $\begin{array}{l}\text { Vaso } m \text {. 1. Florero. 2. Maceta. } \\
\text { Vaso sanitário. Inodoro; } \\
\text { retrete; váter. }\end{array}$ & $\begin{array}{l}\text { vaso } m \text { (para plantas) maceta } f ; \\
\text { (para flores) florero } m \text {; ANAT vaso } \\
m \text {; vaso sanitário retrete } m \text {, wáter } \\
m \text { Amér; vaso sanguíneo vaso } \\
\text { sanguíneo. } \\
\text { [Não confundir vaso (florero) com } \\
\text { o espanhol vaso que em português } \\
\text { é copo. (Ela arrumou as flores no } \\
\text { vaso. Ella arregló las flores en el } \\
\text { florero.)] }\end{array}$ \\
\hline
\end{tabular}

Como explicitado anteriormente na apresentação dos dicionários as entradas

\footnotetext{
${ }^{8}$ Acreditamos que houve um erro de diagramação e/ou revisão do dicionário, pois a palavra oficina tanto em espanhol como em português pertence ao gênero feminino. ${ }^{9}$ A palavra repetida também deve ser um erro de diagramação ou revisão do dicionário.
}

na Língua Portuguesa são mais simples e diretas, não apresentando divisão silábica, sílaba tônica ou definições. Tampouco há indicações de Falsos Amigos no dicionário da Ática e no da Santilhana para as entradas em português. 
O primeiro verbete Apelido está contextualizado apenas no dicionário Larousse que apresenta a comparação entre Apelido (apodo) ${ }^{10}$ e Sobrenome (apellido). O dicionário Santilhana oferece o sinônimo Sobrenombre à palavra apodo em espanhol. Já o dicionário Larousse apresenta o sinônimo Alcunha à palavra apelido na Língua Portuguesa.

Os dicionários Ática e Santilhana introduzem as mesmas equivalências para o segundo Falso Amigo, Escritório. No entanto, o dicionário Ática ainda acrescenta a locução Escritório de advogado, trazendo quatro equivalentes sem contextualizá-los. O dicionário Larousse contextualiza ao demonstrar que para "escritório de casa e de advogados" na Espanha se usa em despacho, e que na América se utiliza estúdio, e ao referir-se a escritório de empresa se emprega oficina. No entanto, na última acepção dá como equivalente a escritório a palavra escritorio com o significado de mesa/ escrivaninha, acepção não usual, o que pode confundir o consulente. Ainda volta ao exemplo da palavra escritorio na entrada do espanhol, o que complica ainda mais a compreensão por parte do consulente.

O vocábulo seguinte, Assinatura, possui os mesmos equivalentes nos três dicionários, contudo, apenas o Larousse esclarece os usos de suas duas acepções. Um dado importante nessa estrada é que a segunda acepção (assinatura de revista ou jornal) o equivalente em espanhol aparece com diferentes ortografias subscripción e suscripción, ambos contemplados pelo Dicionário da Real Academia Espanhola (DRAE).

${ }^{10}$ As palavras entre parênteses estão na Língua Espanhola.
A entrada seguinte, a palavra Oficina, contém os mesmos equivalentes nos dicionários analisados, entretanto o dicionário Larousse ainda introduz um novo equivalente usado no México (refaccionaria), ainda exemplifica o vocábulo, chamando a atenção do consulente para o par de Falsos Amigos: oficina (taller) e escritório (oficina).

O vocábulo Salsa, já mencionado anteriormente, apresenta os mesmos equivalentes nos três dicionários. Apenas o dicionário Larousse novamente faz um contraste entre salsa (perejil) e molho (salsa), seguido de exemplos para ilustrar.

A última entrada avaliada é a palavra é Vaso, cujas acepções e locuções são praticamente equivalentes nos dicionários em questão. Apenas o dicionário Santilhana não menciona a acepção de vaso sanguíneo. A locução vaso sanitário está mencionada em todos os dicionários, não obstante, encontramos pequenas diferenças. O dicionário da Ática nos traz como equivalente apenas inodoro. Já o da Santilhana cita inodoro, retrete e váter ${ }^{11}$. O dicionário Larousse apresenta como equivalentes retrete e de uso na América wáter. Podemos notar a divergência de ortografia nos equivalentes váter e wáter, entretanto wáter não está aceito pelo Dicionário da Real Academia Espanhola.

Não podemos deixar de mencionar que o dicionário Larousse tem erros de diagramação e/ou revisão, o que consideramos uma falha. Talvez para as próximas edições estas sejam corrigidas.

Os dicionários analisados nas entradas da Língua Portuguesa carecem das indicações

\footnotetext{
${ }^{11}$ Váter (do inglês water-closet).
} 
dos Falsos Amigos, pois o estudante de Língua Espanhola durante sua produção necessita de tais informações. Ressaltamos que o uso do dicionário na maioria das vezes é um ato individual, pois durante as aulas o estudante tem em seu professor as respostas às suas dúvidas de imediato. Contudo, quando está fora da sala de aula e necessita produzir em Língua Estrangeira deverá recorrer ao dicionário. Não condenamos que o professor dê respostas imediatistas aos seus alunos durante as aulas, pois devido às poucas horas distribuídas para o estudo da Língua Estrangeira, o professor deve priorizar os encontros para a produção e compreensão oral de seus estudantes. Desta forma, a produção e compreensão escrita podem ser realizadas fora da sala de aula com o auxilio de um bom dicionário.

\section{CONSIDERAÇÕES FINAIS}

Como pudemos analisar por meio de nossas experiências e da literatura referente à pesquisa, o aluno brasileiro ao começar a estudar a Língua Espanhola é um falso iniciante, desta forma, existe a necessidade em se adotar um dicionário de espanhol específico para falantes de português, sobretudo nos níveis iniciais. Os três dicionários analisados estão direcionados ao estudante brasileiro de Língua Espanhola, o que acreditamos ser um avanço dentro da Lexicografia Pedagógica.

Um dado relevante à questão dos Dicionários Bilíngues de Espanhol/ Português e Português/Espanhol diz respeito à quantidade de países falantes da Língua Espanhola e, consequentemente, de sua variedade linguística. Seria impossível abarcar toda a variedade linguística desses países em um dicionário monolíngue, ainda menos possível para um Dicionário Bilíngue e Escolar. Sabemos das limitações quanto ao número de verbetes que contemplam um Dicionário Bilíngue.

Ainda que a Lexicografia Pedagógica e Bilíngue tenham trazido contribuições para os Dicionários Escolares Bilíngues, os dicionários analisados carecem de melhorias principalmente no que diz respeito às entradas da Língua Portuguesa. Enfatizo novamente essa necessidade, sobretudo durante a produção escrita, realizada fora da sala de aula, o estudante precisará recorrer à Língua Materna para chegar à Língua Estrangeira.

Os três dicionários apresentam os Falsos Amigos e dão um tratamento adequado à questão. Mesmo com falhas, são bons instrumentos para auxiliar o estudante brasileiro aprendiz de Língua Espanhola.

Finalmente, ressaltamos que há falta de preparo do professor para que este auxilie seus alunos quanto ao uso do dicionário em sala de aula. Para sanar essa lacuna sugerimos a introdução de estudos lexicográficos na disciplina de Estudos Linguísticos durante a graduação em licenciatura dos cursos de Letras.

\section{REFERÊNCIA DO CORPUS}

DÍAS, M.; GARCÍA-TALAVERA, M. Dicionário Santilhana para estudantes: espanhol português, português / espanhol. $2^{\circ}$ ed. rev. e ampl., São Paulo, Ed. Moderna, 2008. 
ERES FERNÁNDEZ, G. \& FLAVIAN, E. Minidicionário espanhol português, português / espanhol. $2^{\circ}$ ed., São Paulo, Ed. Ática, 1995.

GALVEZ, J. A. (org. editorial) Minidicionário Larousse espanhol português, português / espanhol. $2^{\circ}$ ed., São Paulo, Larousse do Brasil, 2009.

\section{REFERÊNCIAS DAS OBRAS UTILIZADAS}

ANDRADE NETA, N. F.Aprender español es fácil porque hablo portugués: Ventajas y desventajas de los brasileños para aprender español. In: Cuadernos Cervantes. SD. Disponível em: <http://www.cuadernoscervantes.com/lc portugues.html>

BIDERMAN, M. T. C. As ciências do Léxico. In: ISQUERDO, A. N. (Org.); OLIVEIRA, A. M. P. P. de (Org.). As Ciências do Léxico: lexicologia, lexicografia e terminologia. $1^{a}$. ed. Campo Grande: Editora da UFMS, 1998. v. 01. 263 p.

BUGUEÑO MIRANDA, F. V. Os dicionários de falsos amigos. Anais do CELSUL, 2008.

CEOLIN, R. Falsos Amigos Estruturais entre o Português e o Castelhano. In: Revista de Philologica Românica, 2003. http://www. romaniaminor.net/ianua

CONTRERAS, M. As armadilhas que podem ser oferecidas pela proximidade dos idiomas - A interlíngua oferecida como insumo nas aulas de Língua Espanhola como LE. Dissertação de Mestrado. Universidade Católica de Pelotas, Pelotas, RS, 1998.

DRAE, Diccionario de la Real Academia Española, $22^{a}$ edición. Disponível em: www. rae.es

DURAN, M. S. Dicionários bilíngües pedagógicos: análise, reflexões e propostas. 2004. Dissertação (Mestrado em Estudos Lingüísticos) Instituto de Biociências, Letras e Ciências Exatas de São José do Rio Preto, Universidade Estadual Paulista.

FEIJÓ HOYOS, B. L.; HOYOS ANDRADE, R. Dicionário de falsos amigos. São Paulo, Ed. Página Aberta: Consejería de Educación de la Embajada de España, 1992.

FREGOLENTE, R. A. Dicionários Bilíngües espanhol/português - português/ espanhol: uma confrontação para o ensino de línguas. Letras \& Letras, Uberlândia 20 (1) 197-210, jan./ jun. 2004.

FERREIRA, F.A. D. O uso do dicionário bilíngue no processo de compreensão de textos por alunos iniciantes de espanhol LE. Dissertação de Mestrado. Universidade de Brasília, 2006.

KREBS, M. E. Um olhar para interferência dos heterossemânticos na aprendizagem do espanhol por falantes nativos de português brasileiro: um estudo de caso. Dissertação de Mestrado. Universidade Católica de Pelotas, Pelotas, RS, 2007.

SCHMITZ, R. A problemática dos dicionários bilíngues. OLIVEIRA, A. M. P. de; ISQUERDO, A. N. As ciências do léxico: lexicologia, lexicografia, terminologia. 2ed. Campo Grande, MS: Ed. UFMS, 2001. Vol. 1, p. 161-170. VITA, C. P. Os conceitos de falsos amigos, falsos cognatos e heterossemânticos: a discussão de uma sinonímia. Dissertação de Mestrado. Universidade de São Paulo, 2004.

VITAL, J. B. O uso do dicionário em aulas de inglês no Ensino Fundamental: entre a competência lexical ideal e o consulente real. Dissertação de Mestrado - Universidade Federal de Mato Grosso do Sul, Mestrado em Letras. Três Lagoas, MS, 2006.

WERNER, R. El diccionario bilingüe y la enseñanza del español como lengua extranjera. In: SIGNUM: Estud. Ling., Londrina, n. 9 / 1, p. 205-238, jun. 2006. 
XATARA, C. M. Os dicionários bilíngües e o problema da tradução. In: OLIVEIRA, A M. P. P.; ISQUERDO, A. N. (org.). As ciências do léxico. Campo Grande: Ed. UFMS, 2001, p. 181188. ; BEVILACQUA, C. R.; HUMBÉ, P. R. M. (orgs.) Dicionários na teoria e na prática: como e para quem são feitos. São Paulo, Parábola Editorial, 2011.

Recebido para publicação em 21 ago. 2016.

Aceito para publicação em 01 out. 2016. 